\title{
Organização espacial das caieiras e fornos de cal no campo calcário Aroeiras, municípios de Coreaú e Sobral (CE): passado e presente
}

\author{
Spatial organization of caieiras and lime kilns in Aroeiras limestone field, \\ municipalities of Coreaú and Sobral (CE): past and present
}

\author{
ALBUQUERQUE ${ }^{1}$, F. N. B.
}

nataniel.albuquerque@ifce.edu.br

\begin{abstract}
Resumo
A apropriação dos elementos e aspectos da natureza dos geossistemas como recurso natural definem os sistemas ambientais e sua expressão geográfica, as organizações espaciais. Diante desse contexto, o presente artigo tem por objetivo analisar a organização espacial das caieiras e fornos de cal, unidades rudimentares e tradicionais de produção da cal, na paisagem do geossistema do campo calcário Aroeiras nos municípios de Coreaú e Sobral, região Noroeste do Estado do Ceará. A identificação das caieiras e fornos de cal se deu mediante análise de imagem de satélite e trabalho de campo no ano de 2015. Como resultado da pesquisa, foram identificadas 73 unidades de produção de cal, sendo 71 caieiras e 02 fornos de cal classificadas em ativas (19), desativadas (19) e destruídas (35) no campo Aroeiras e adjacências distribuídas pelo quadrilátero calcário delimitado pelos distritos de Aroeiras - Aprazível - São Joé do Torto - Ubaúna. As unidades produtivas estão organizadas espacialmente em 04 núcleos de produção e uma unidade isolada: Vila Basílio - Pau D’Arco, Queimadas - Visitação, Ubaúna - Campo do Meio, Ipu dos Lopes - Três Lagoas, São José do Torto e, Coreaú. Podemos concluir que apenas 1/3 das unidades estão em funcionamento, das quais 53\% encontram-se no núcleo de produção Vila Basílio - Pau D'Arco ao longo de $14 \mathrm{~km}$ da rodovia CE-364 e cada vez mais distantes dos núcleos populacionais evidenciando um distanciamento dos núcleos populacionais e a concentração nos principais eixos rodoviários em função dos custos de transporte e da poluição causada pela combustão dos fornos às residências.
\end{abstract}

Palavras-chave: Organização espacial. Calcário. Caieira. Cal.

\begin{abstract}
The appropriation of the elements and aspects of the nature of geosystems as a natural resource defines the environmental systems and their geographical expression, the spatial organizations. Given this context, the present article aims to analyze the spatial organization of the caieiras and lime kilns, rudimentary and traditional lime production units, in the landscape of the Aroeiras limestone geosystem in the municipalities of Coreaú and Sobral, Northwest of the State of Ceará. The identification of the caieiras and lime kilns was made by satellite image analysis and fieldwork in 2015. As a result of the research, 73 lime production units were identified, being 71 caieiras and 02 lime kilns classified as active (19), deactivated (19) and destroyed (35) in the Aroeiras field and adjacency distributed by the limestone quadrangle bounded by the districts of Aroeiras - Aprazível - São Joé do Torto - Ubaúna. The productive units are spatially organized into 04 production nucleus and one isolated unit: Vila Basílio - Pau D’Arco, Queimadas - Visitation, Ubauna - Campo do Meio, Ipu dos Lopes - Três Lagoas, São José do Torto e, Coreaú. We can conclude that only 1/3 of the units are in operation, of which 53\% are in the Vila Basílio - Pau D'Arco production nucleus along $14 \mathrm{~km}$ of the CE-364 highway and increasingly distant from the population nuclei, showing a distance from the population and concentration on the main road axes as a function of transport costs and pollution caused by combustion of furnaces in households.
\end{abstract}

Keywords: Spatial organization. Limestone. Lime kiln. Quicklime. 


\section{INTRODUÇÃO}

A apropriação de recursos naturais, de origem animal, vegetal e mineral, ao longo da história da humanidade e, consequentemente, a sua localização e suas interações espaciais, sociais e econômicas tem organizado territórios e propiciado acumulação de riquezas e desigualdades sociais, gerando conflitos em diferentes civilizações.

O território está organizado para a realização concomitante de várias atividades de apropriação dos recursos naturais nas mais diversas tipologias de geossistemas. Essas atividades se estabelecem em setores naturais específicos, ou seja, em regiões de influência delimitadas muitas vezes por fronteiras tênues e/ou sobrepostas que obedecem os mais variados critérios, sejam eles naturais e/ou sociais, impondo-lhes restrições dos mais variados graus ao uso da terra e de seus recursos.

Dentro desse contexto, agentes sociais e/ou etapas do processo de apropriação dispostos espacialmente interagem a partir de fluxos de matéria, energia e informação conferindo dinâmica à organização espacial. Dessa forma, cada atividade pode constituir uma organização espacial específica ou conjunta com as demais, sempre passível de contradições e conflitos.

A organização espacial de uma região estrutura-se a partir da disposição no espaço de elementos e aspectos da natureza disponíveis no geossistema que, ao serem valorados e apropriados direta e indiretamente pela sociedade são transformados em recurso natural, como o calcário, rocha apropriada diretamente para a produção da cal e cimento, por exemplo.

O geossistema da Depressão Interplanáltica Semiárida do Alto Coreaú (DISAC), localizado na região noroeste do Estado do Ceará, entre as barreiras orográficas da Serra da Meruoca e do Planalto da Ibiapaba é marcado, dentre outras características, pela ocorrência de rochas carbonáticas do Grupo Ubajara em 03 campos calcários, os quais são explorados com mais intensidade desde a segunda metade do século XX para a produção artesanal da cal, por meio de unidades produtivas rudimentares, denominadas popularmente de caieira e forno de $\mathrm{cal}$, as quais tem como matriz energética a lenha da Caatinga (ALBUQUERQUE, 2015).

A produção da cal está entre as atividades mais antigas da humanidade, utilizada na construção civil, agricultura, tecidos, entre outros usos, desde os egípcios na construção das pirâmides do Egito em 3.000 a.C. a partir de uma mistura de cal e gesso (SINDICAL, 2019).

Diante desse contexto, o objetivo do artigo é analisar a organização espacial da produção da cal nos municípios de Coreaú e Sobral, Estado do Ceará (figura 01), a partir da 
distribuição espacial das caieiras e fornos de cal e a formação de núcleos produtivos no geossistema do campo de calcário Aroeiras e adjacências.

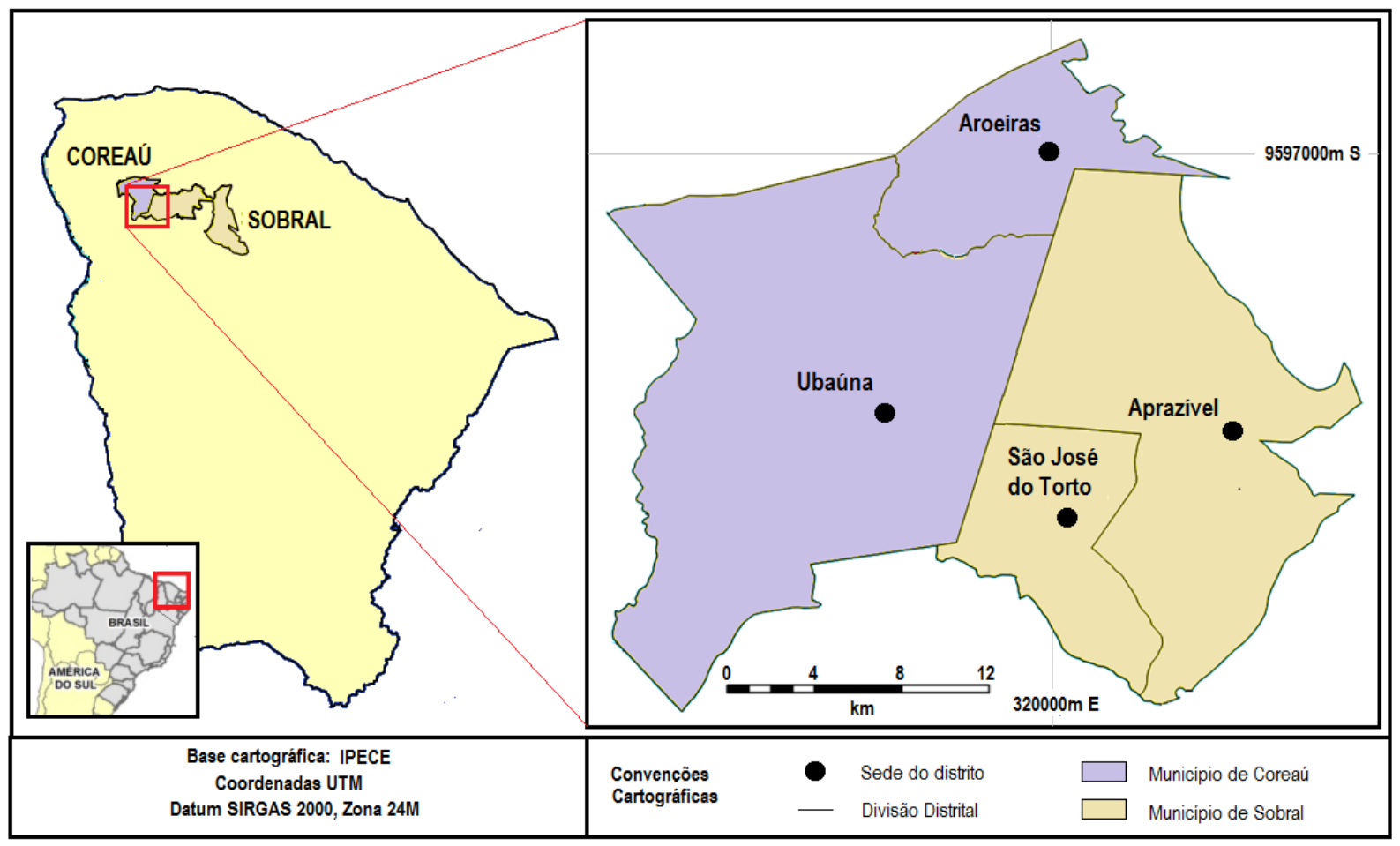

Figura 01: Localização da área de estudo. Fonte: Nataniel Albuquerque, 2019.

\section{GEOSSISTEMA E ORGANIZAÇÃO ESPACIAL: NATUREZA E AÇÃO ANTROPOGÊNICA NA PERSPECTIVA GEOGRÁFICA}

Do ponto de vista conceitual e teórico-metodológico, a pesquisa está fundamentada na concepção naturalista do geossistema de Sochava (1977) e Bertrand (1997). No entanto, o geossistema configura-se como uma unidade espacial de transição entre os níveis inferiores e superiores da paisagem como propõe Bertrand (1972) e reforçada por Monteiro (2003) ao ressaltar a importância da escala regional dos estudos geográficos colocando, portanto os sistemas ambientais e, sua expressão geográfica, a organização espacial (CHRISTOFOLETTI, 1999 e PEREZ FILHO, 2008) como unidades de paisagem e planejamento no ordenamento territorial (RODRIGUEZ e SILVA, 2019).

O geossistema configura-se como um sistema natural de dimensão variada, identificável no tempo e no espaço, onde há uma forte interrelação entre seus componentes colocando-se como um conceito importante no âmbito da Geografia, especialmente, na 
Geografia Física para explicar a dinâmica e organização dos elementos da natureza, condição sine qua non para o entendimento da organização espacial dos sistemas ambientais.

A teoria geossistêmica, aplicação geográfica da Teoria Geral dos Sistemas, é uma das tentativas da Geografia em lidar com os princípios da interdisciplinaridade, síntese, abordagem multiescalar, dinâmica e prognoses (RODRIGUES, 2001).

No modelo geossistêmico russo-soviético de Victor Sochava, o geossistema também é denominado de sistema geográfico ou complexo natural territorial. Sochava (1977) define geossistema como "formações naturais, experimentando, sob certa forma, o impacto dos ambientes social, econômico e tecnogênico" configurando-se como uma classe peculiar de sistemas dinâmicos abertos e hierarquicamente organizados.

No final do século passado, o francês Georges Bertrand (1997) propõe uma reformulação ao seu modelo teórico original na tentativa de responder à complexidade dos sistemas e a busca por uma paradigma geográfico, lançando o sistema tripolar Geossistema, Território e Paisagem (GTP), aproximando seu modelo inicial à concepção geossistêmica natural da escola soviética.

$\mathrm{Na}$ atual concepção, o GTP consiste num sistema com 03 "entradas" possíveis em um mesmo sistema especulando sobre finalizações possíveis e as hierarquias internas assim arquitetado: geossistema, fonte ou "entrada" naturalista; território, recurso ou "entrada" socioeconômica, e; paisagem, ressurgimento ou "entrada" sociocultural.

Do ponto de vista escalar, a proposição francesa de Bertrand (1972), apresenta uma grande contribuição ao propor um sistema taxonômico que permite classificar as paisagens em seis níveis temporo-espaciais, divididos em escalas superiores (zona, domínio e região) e inferiores (geossistema, geofácies e geótopo) de paisagem, sendo cada nível considerado uma "unidade de paisagem" definida em função da escala.

Troppmair e Galina (2006) ressaltam que a ação dos sistemas sociais sobre o geossistema provoca pequenas alterações em algumas características específicas, apenas perceptíveis na micro-escala e nunca numa escala mais abrangente a ponto de transformar, descaracterizar ou deformar totalmente o geossistema.

\footnotetext{
"Os sistemas antrópicos, por meio do uso e da ocupação das terras, usufruem dos potenciais dos geossistemas e modificam os fluxos de matéria e energia existentes, rompendo seu equilíbrio e alterando, assim, sua expressão espacial, com a consequente criação de novas organizações espaciais (PEREZ FILHO, 2008, p. $364) "$.
}

Como afirma Perez Filho (2008), no contexto geográfico, a relação entre os sistemas antrópicos e os geossistemas ou sistemas ambientais físicos origina a organização espacial. 
Dessa forma, entendemos a organização espacial como objeto de estudo da Geografia, portanto, como a expressão geográfica dos sistemas ambientais que se apresentam em diferentes escalas espaciais com mais ou menos elementos culturais presentes.

No âmbito da Geografia, a organização assume uma dimensão espacial configurandose como a expressão geográfica do sistema ambiental, produto da integração da sociedade e natureza. Dessa forma, o sistema ambiental comporta-se como um metassistema, o qual resulta da integração dos "independentes" subsistemas naturais e sociais (figura 02).

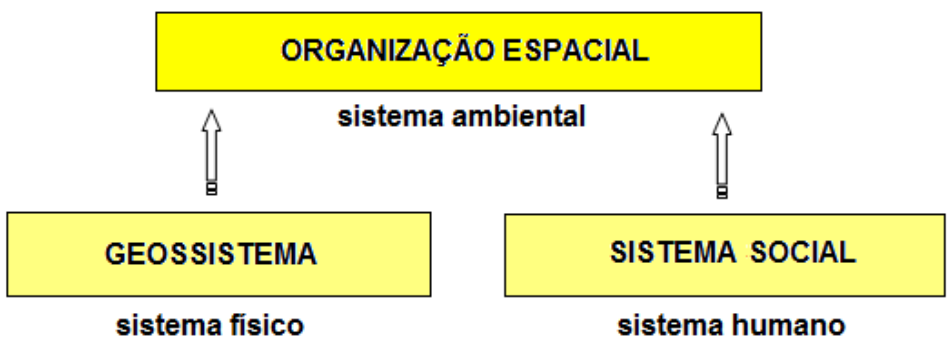

Figura 02: Subsistemas do sistema ambiental num viés geográfico. Fonte: Adaptado de Christofoletti (1999).

Segundo Rodriguez e Silva (2013), a organização espacial possui entre as principais propriedades, a estrutura e a disposição dos elementos na superfície do globo, bem como suas funções e relações que ocorrem no espaço.

A metáfora utilizada por Corrêa (2000, p. 59) sintetiza e ilustra bem a aplicação do conceito de organização espacial.

\begin{abstract}
"Imagine um ginásio esportivo polivalente. A quadra está organizada para ali realizarem-se jogos de vôlei, basquete e futebol de salão. Para cada esporte (atividade), a quadra (Superfície da terra) tem um zoneamento especifico (regiões), áreas limitadas por linhas onde há certas restrições ou penalidades. Para cada jogo, há regras (leis, códigos morais) e um juiz (aparelho repressor). Cada jogador (agente realizador de uma atividade) tem uma posição dentro da quadra (localização da atividade) e há caminhos a serem percorridos pelo jogador e a bola (fluxos materiais ou não). Em outras palavras, para cada esporte existe uma organização espacial especifica...".
\end{abstract}

Em outras palavras, a organização como um sistema de variáveis mutuamente dependentes (BERTALANFFY, 2010) é uma das principais características da TGS. Segundo Ashby (1962 apud MORIN, 2008), um componente organizacional está presente quando uma relação entre duas entidades A e B torna-se condicional a um valor ou um estado C.

Na concepção de Sochava (1977), os sistemas ambientais seriam os sistemas totais, pois, representam um complexo interativo de diferentes classes de sistemas com seus parâmetros espaciais, temporais e funcionais. Essa relação se dá pela influência de um sistema sobre o outro ou como ressalta Marten (2001, s/p), por meio da coadaptação. 


\begin{abstract}
"Los sistemas sociales humanos se adaptan a su medio ambiente, al ecosistema, y los ecosistemas se adaptan a los sistemas sociales humanos. Los ecosistemas naturales, y las porciones naturales de los ecosistemas agrícolas y urbanos, responden a las intervenciones humanas haciendo ajustes que contribuyen a la supervivencia. Los ecosistemas agrícolas y urbanos también evolucionan y se adaptan al sistema social en la medida en que las personas los modifican para que se adecúen a su sociedad cambiante".
\end{abstract}

Como essa relação entre as duas macrodimensões da realidade pode se dar desde o nível biológico ao sociológico, a organização espacial configura como o recorte do campo de análise da Geografia, assim, o físico e o humano, na dimensão geográfica, assumem a perspectiva do natural e social, respectivamente. Como resultado dessa interação, num nível superior dos sistemas social e natural, nesse caso, subsistemas, teremos o sistema ambiental.

Todas os métodos ou etapas de integração de diferentes dimensões da realidade dispostas até aqui, situam-se ao nível da ciência, no caso da nossa pesquisa, da Geografia. No entanto, Monteiro (2003), remete-se ao conhecimento geográfico gerado e passível de ser aplicado, por exemplo, no ordenamento territorial que encontra-se ao nível da política. Vale ressaltar que à ciência cabe estudar o ordenamento territorial e não planejá-lo ou gerí-lo, ficando essa etapa a cargo dos tomadores de decisão, muito embora, a base empírica das pesquisas aflorem de problemáticas do cotidiano.

\title{
3. PROCEDIMENTOS METODOLÓGICOS
}

A metodologia da pesquisa consistiu, inicialmente, na delimitação do campo calcário Aroeiras do Grupo Ubajara, o geossistema em estudo mediante base cartográfica da Companhia de Pesquisa de Recursos Naturais (CPRM) na escala 1:1.000.000.

Após a delimitação do geossistema, no ano de 2015, deu-se início a identificação de caieiras e fornos de cal mediante análise de imagens de satélite do software Google Earth com checagem a partir de trabalhos de campo utilizando um receptor de GSP Garmin. A resposta espectral singular das unidades produtivas (branco da cal depositada nos pátios a céu aberto) e das áreas de explotação (cinza-azulado das cavas e ramificações deixadas pelos caminhos que ligam as cavas às principais vicinais da região) nos auxiliou na localização das caieiras.

As unidades produtivas, caieiras e fornos de cal, foram classificadas em ativas, desativadas e destruídas a fim de compreender melhor a dinâmica produtiva e espacial da atividade. As caieiras destruídas foram identificadas a partir de observações minuciosas de campo e relatos orais obtidos com moradores da região. 
Após o levantameto das mesmas, as unidades foram agrupadas em núcleos produtivos da cal segundo critérios como a distância entre as mesmas e as principais vias de acesso às cavas de calcário e ao escoamento da produção.

\section{DISTRIBUIÇÃO ESPACIAL DAS CAIEIRAS E FORNOS DE CAL NO GEOSSISTEMA DO CAMPO DE CALCÁRIO AROEIRAS}

No contexto natural da Depressão Interplanáltica Semiárida do Alto Coreaú (DISAC), inserido entre o Maciço Residual Úmido da Meruoca, a leste e, o Planalto da Ibiapaba, a oeste, na porção noroeste do Estado do Ceará, está localizado a área "FrecheirinhaAprazível", 01 dos 13 campos de rochas carbonáticas metassedimentares do Estado apontados pelo Projeto Radam Brasil (BRASIL, 1981).

Numa escala de maior detalhe, a área possui 03 campos calcários: Campo Frecheirinha $\left(115 \mathrm{~km}^{2}\right)$, Campo Aroeiras $\left(79 \mathrm{~km}^{2}\right)$ e Campo Penanduba $\left(37 \mathrm{~km}^{2}\right)$ totalizando uma área de $231 \mathrm{~km}^{2}$ distribuída pelos municípios de Coreaú, Frecheirinha, Sobral e Ubajara constituindo um geossistema, uma unidade de paisagem regional marcada pela explotação do calcário para a fabricação artesanal da cal em unidades produtivas rudimentares denominadas popularmente de caieiras e fornos de cal (ALBUQUERQUE, 2015) (figura 03).

Em 1981, os relatórios do projeto Radam Brasil (BRASIL, 1981, p. 155) já demonstravam a importância significativa da atividade minerária nos campos calcários Frecheirinha e Aroeiras:

"Os calcários deste campo metalogenético [Campo Frecheirinha] vêm sendo utilizados de forma ainda rudimentar em pequenas caieiras com vistas ao fabrico da cal".

“[Campo Aroeira] é o segundo campo metalogenético de natureza calcária desta área. Do ponto de vista econômico é, atualmente, o mais importante. Seus calcários são utilizados para a fabricação de cimento pela Companhia Cearense de Cimento Portland cujas instalações têm capacidade de produção de 100.000 t/ano de cimento".

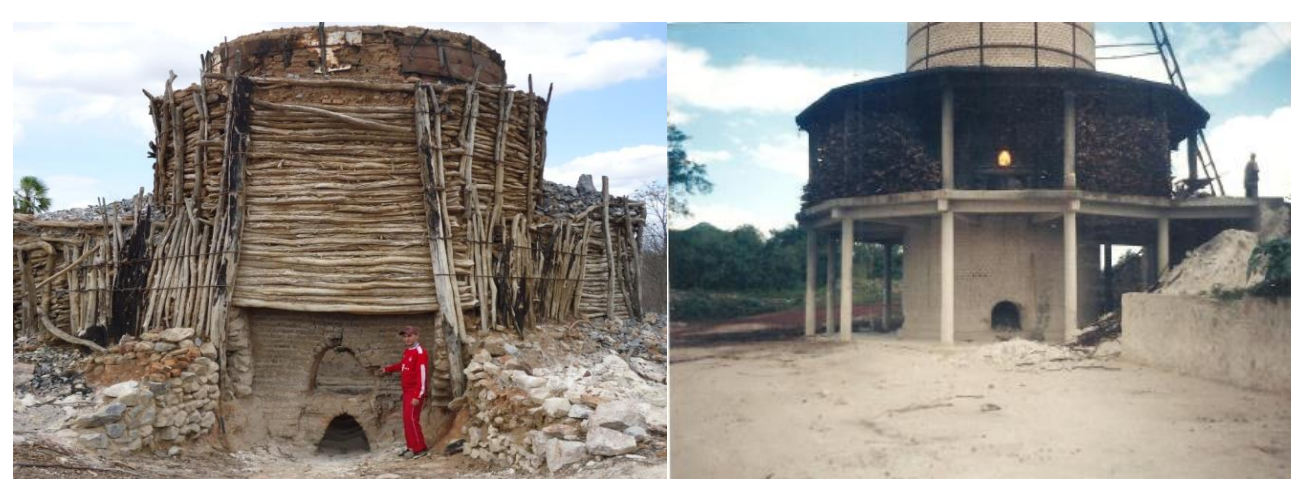

Figura 03: Vista geral de uma caieira e um forno de cal vertical para calcinação do calcário, respectivamente, nas localidades de Aroeiras e Vila Basílio (Coreaú). Fonte: Nataniel Albuquerque $(2014 ; 2003)$. 
Na mesma década, em 1984, o Banco do Nordeste do Brasil (1987) identifica as 13 principais áreas com a presença de indústrias de calcários e dolomitos no Nordeste denominadas de área produtora tradicional (APT), destacando a região formada pelos municípios de Coreaú e Frecheirinha (figura 04) que, juntamente com as demais áreas do Ceará, compõem o Estado com o maior número de unidades produtoras totalizando 32,6\%, seguido da Paraíba com 17,2\%. No Ceará, o calcário é encontrado em 21 municípios, sendo a maior concentração em Limoeiro do Norte e Sobral (AMARAL FILHO e SCIPIÃO, 2004).

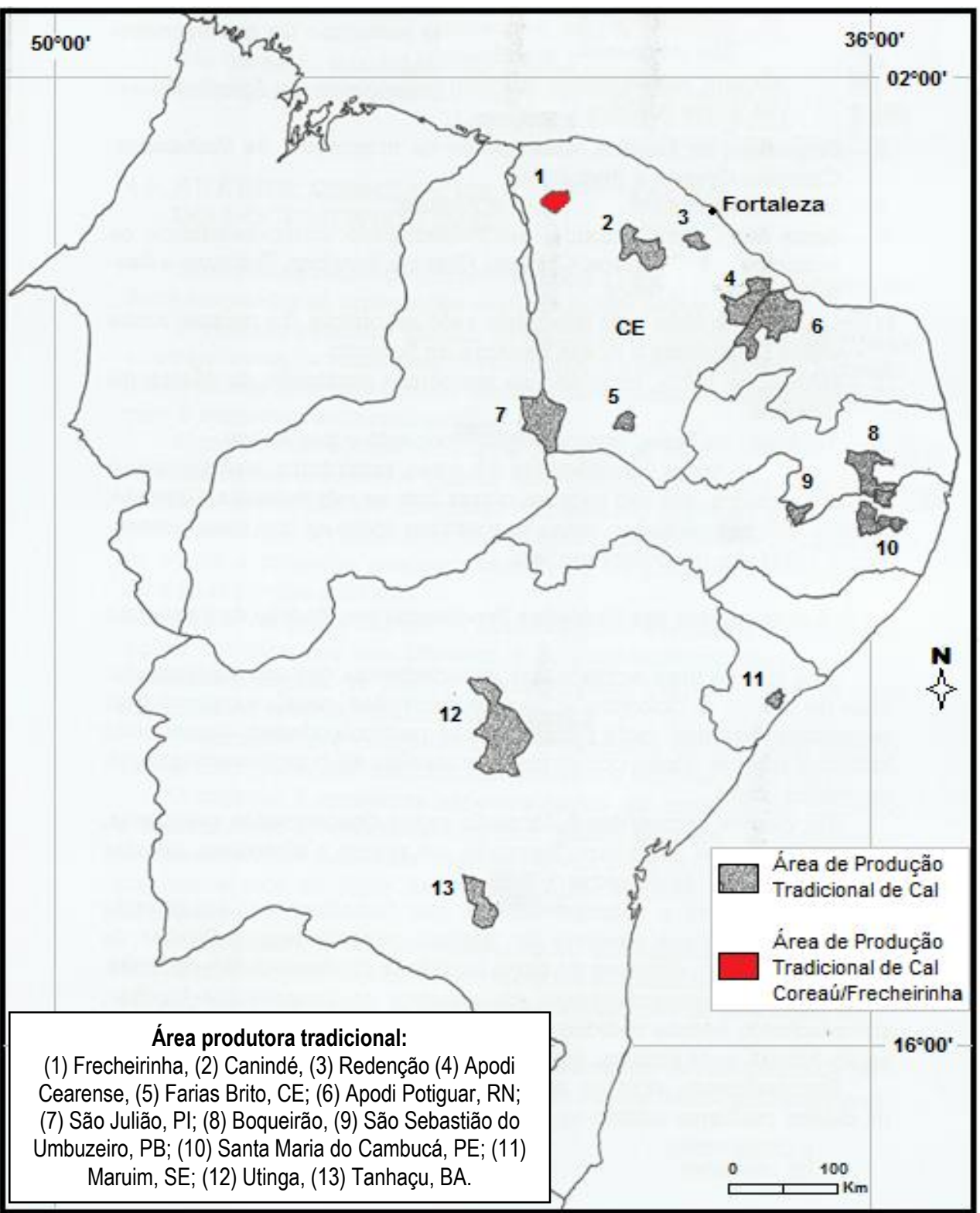

Figura 04: Áreas produtoras de calcários e dolomitos no Nordeste (1984). Fonte: BNB (1987). 
Dentre as áreas produtoras identificadas em 1984, a APT formada pelos municípios de Frecheirinha e Coreaú era a $3^{\mathrm{a}}$ com o maior número de caieiras da região Nordeste, com 21 unidades, atrás apenas da APT São Julião/PI (36) e Apodi Cearense (29) (BNB, 1987).

O estudo realizado em 1984 por BNB (1987) identificou 22 unidades de produção da cal, das quais 20 eram caieiras (todas sem registro), sendo 12 localizadas em Coreaú e 08 em Frecheirinha. As únicas 02 empresas (pessoa jurídica), por sua vez, localizavam-se no município de Frecheirinha sendo uma aberta antes de 1960 e a outra na década de 1970, revelando assim, o baixo investimento e a informalidade do setor (tabela 01).

Tabela 01: Período de abertura (\%) de caieiras e empresas por períodos na região de Coreaú/Frecheirinha e no Estado do Ceará. Fonte: Adaptado de BNB (1987).

\begin{tabular}{|c|c|c|c|c|c|}
\hline \multirow{2}{*}{ Tipo de Unidade } & \multicolumn{3}{|c|}{ Período do início de funcionamento } & \multirow{2}{*}{ Total } \\
\cline { 2 - 5 } & Até 1960 & $\mathbf{1 9 6 1 - 1 9 7 0}$ & $\mathbf{1 9 7 1 - 1 9 8 0}$ & $\mathbf{1 9 8 1 - \mathbf { 1 9 8 4 }}$ & \\
\hline Caieira & - & 06 & 07 & 06 & $20^{*}$ \\
\hline Empresa & 01 & - & 01 & - & 02 \\
\hline Total de Unidades & $\mathbf{0 1}$ & $\mathbf{0 6}$ & $\mathbf{0 8}$ & $\mathbf{0 6}$ & 22* \\
\hline Total Região (\%) & 4,8 & 28,6 & 38,0 & 28,6 & \\
\hline Total Ceará (\%) & 11,4 & 17,6 & 43,2 & 27,0 & \\
\hline
\end{tabular}

*Uma caieira não foi entrevistada.

Vale ressaltar dois aspectos do ponto de vista espacial e metodológico no estudo de BNB (1987). O primeiro consiste no fato das unidades produtivas do município de Sobral não terem sido identificadas, fato este explicado talvez pela distância das caieiras em relação às sedes do distrito de Aprazível e do município de Sobral, não estabelecendo uma identidade territorial. O segundo, por sua vez, diz respeito a referência à cidade de Frecheirinha e o entorno do distrito de Aroeiras (Coreaú) como sendo as áreas de maior densidade de caieiras da região, não sendo levantadas possivelmente as inúmeras caieiras dispersas em várias localidades distantes dos principais eixos rodoviários devido ao difícil acesso, principalmente no período chuvoso tendo sido subestimado o real potencial produtivo regional.

Três décadas depois, Albuquerque (2015) identifica 23 caieiras em funcionamento na DISAC, das quais 19 encontram-se no campo Aroeiras e adjacências e, apenas 04, no campo Frecheirinha, enquanto o campo Penanduba, o de menor dimensão, não possui nenhuma unidade produtiva em funcionamento.

No campo Aroeiras, objeto de análise da presente pesquisa, tem se tornado nos últimos anos o campo calcário de maior importância econômica e espacial, pois concentra o maior número de caieiras e fornos de cal da região, além de possuir a área de explotação mineral da fábrica de cimento do Grupo Votorantim, com unidade fabril na cidade de Sobral. 
Em 2015, no campo calcário Aroeiras e sua área de influência foram catalogadas 73 unidades de produção da cal, sendo 71 caieiras e 02 fornos de cal (figura 05). Das 73 unidades identificadas, apenas $26 \%$ encontravam-se em funcionamento, predominado as unidades produtivas desativadas (25\%) e, principalmente, as destruídas (49\%) que compõem a metade das unidades levantadas.

Do ponto de vista da distribuição espacial por municípios e distritos, podemos constatar uma maior concentração de caieiras de diferentes estágios de funcionamento no município de Coreaú. No entanto, no recorte distrital, as caieiras estão localizadas igualmente nos territórios dos distritos de Ubaúna e Aroeiras (Coreaú) e Aprazível (Sobral), esse último com destaque para a localidade de Pedra de Fogo. Apenas 01 (uma) unidade produtiva, mais exatamente o forno de cal da cidade de Coreaú (tabela 02) não está nas adjacências do campo Aroeiras, mas foi levantado na pesquisa devido a ligação com o referido geossistema no que tange à origem da rocha e utilização da CE-364 como via de escoamento da produção.

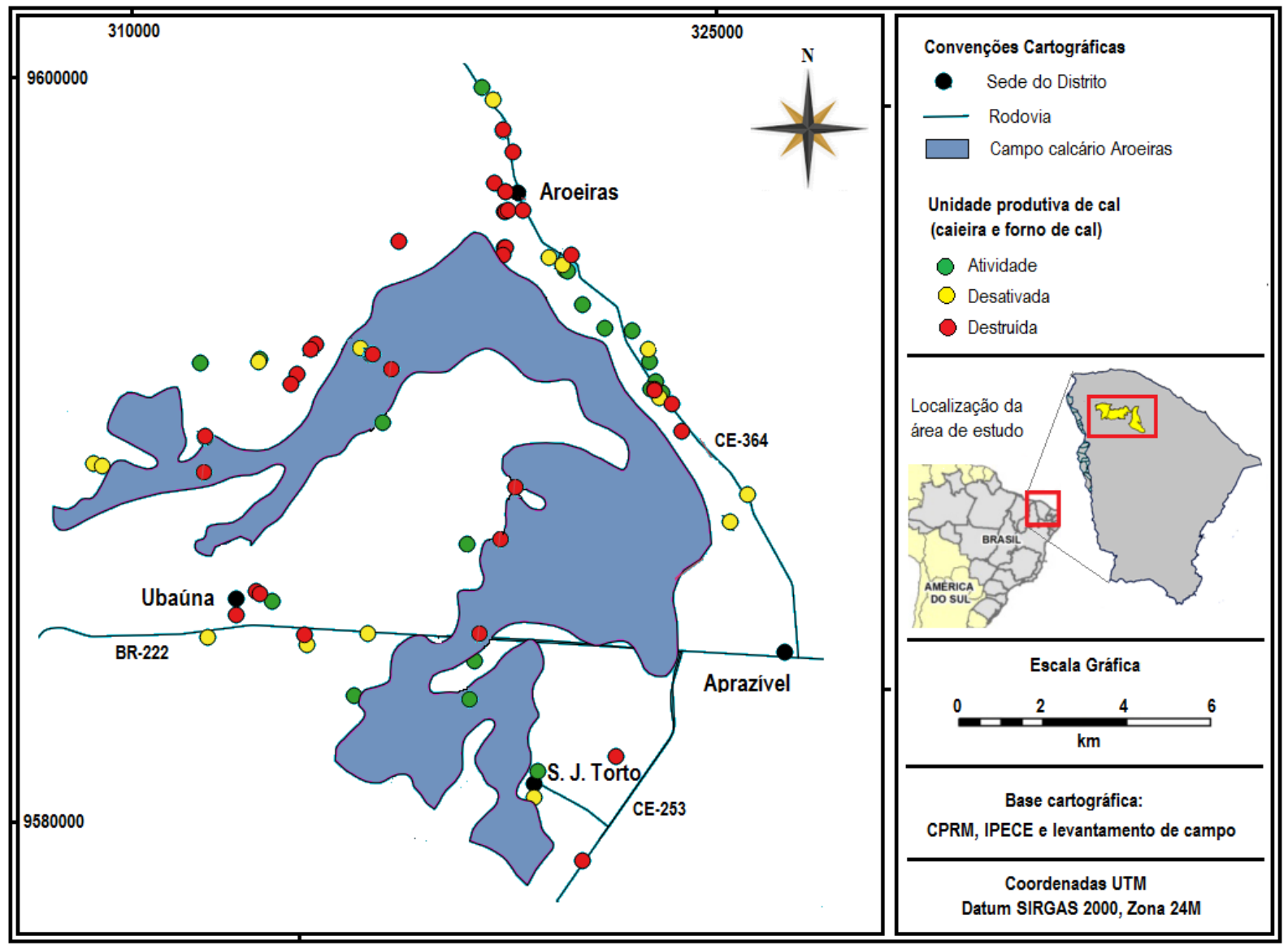

Figura 05: Distribuição espacial das unidades de produção da cal no contexto do campo calcário Aroeiras (2015). Fonte: Nataniel Albuquerque, 2019. 
Tabela 02: Distribuição espacial das unidades de produção por município/distrito. Fonte: Levantamento de campo (2015).

\begin{tabular}{|l|l|c|c|c|c|}
\hline \multirow{2}{*}{ Município } & \multirow{2}{*}{ Distrito } & \multicolumn{3}{|c|}{ Caieira e Forno de cal } & \multirow{2}{*}{ Total } \\
\cline { 3 - 6 } & & Funcionamento & Desativada & Destruída & \\
\hline \multirow{3}{*}{ Coreaú } & Sede* & -- & $01^{*}$ & -- & 01 \\
\cline { 2 - 6 } & Aroeiras & 01 & $04^{*}$ & 17 & 22 \\
\cline { 2 - 6 } & Ubaúna & 06 & 06 & 10 & 22 \\
\hline \multirow{2}{*}{ Sobral } & Aprazível & 09 & 07 & 06 & 22 \\
\cline { 2 - 6 } & S. J. do Torto & 03 & 01 & 02 & 06 \\
\hline \multicolumn{2}{|l}{} & $\mathbf{1 9}$ & $\mathbf{1 9}$ & $\mathbf{3 5}$ & $\mathbf{7 3}$ \\
\hline
\end{tabular}

*Forno de cal.

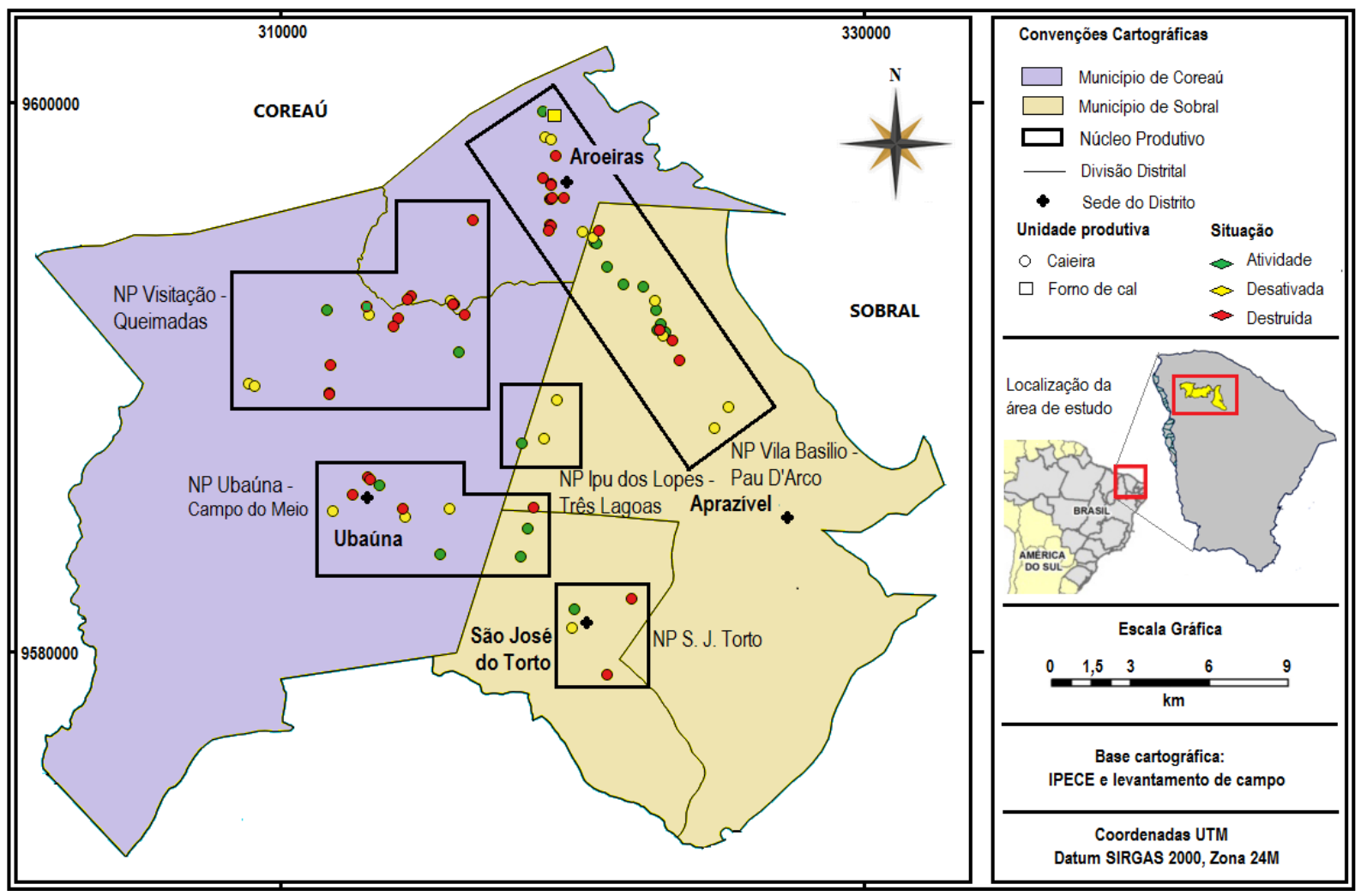

Figura 06: Mapa de distribuição espacial das caieiras e fornos de cal do campo calcário Aroeiras por município/distrito e núcleos produtivos (2015). Fonte: Elaborado pelo autor, 2019.

No universo das unidades produtivas desativadas vale destacar a existência de 02 fornos de cal de alvenaria e de grande capacidade de produção desativados, um situado nas imediações da cidade de Coreaú e, o outro, na localidade de Vila Basílio (distrito de Aroeiras) (figura 07), ambos às margens da CE-364 construídos na década de 1990.

A distribuição espacial das caieiras e fornos de cal nos permite agrupá-las em zonas que denominamos de núcleos produtivos da cal (NPC) levando em consideração aspectos como a distância, vias de acesso e áreas de explotação da rocha. No campo Aroeiras identificamos 05 núcleos produtivos e um forno de cal isolado (tabela 03). 
Podemos perceber que metade das caieiras e o forno de cal, independente de estarem funcionando, desativados ou destruídos estão concentrados no núcleo produtivo Vila Basílio Pau D'Arco ao longo de $14 \mathrm{~km}$ da CE-364. Considerando apenas as caieiras ativas, 10 das 19 unidades mapeadas no campo Aroeiras estavam no referido núcleo, mantendo aproximadamente os mesmos percentuais em relação aos demais núcleos produtivos.

Tabela 03: Número de caieiras/fornos por núcleo de produção da cal no Campo Aroeiras. Fonte: Levantamento de campo (2015).

\begin{tabular}{|l|c|c|c|c|}
\hline \multirow{2}{*}{ Núcleo produtivo da cal } & \multicolumn{4}{c|}{ Caieira ou Forno de Cal } \\
\cline { 2 - 5 } & Ativa & Desativada & Destruída & Total \\
\hline Vila Basílio - Pau D’Arco & 10 & $08^{*}$ & 18 & $\mathbf{3 6}$ \\
\hline Queimadas - Visitação & 03 & 04 & 10 & $\mathbf{1 7}$ \\
\hline Ubaúna - Campo do Meio & 04 & 03 & 05 & $\mathbf{1 2}$ \\
\hline Três Lagoas - Ipu dos Lopes & 01 & 02 & --- & $\mathbf{0 3}$ \\
\hline São José do Torto & 01 & 01 & 02 & $\mathbf{0 4}$ \\
\hline Coreaú** & --- & $01^{*}$ & --- & $\mathbf{0 1}$ \\
\hline Total & $\mathbf{1 9}$ & $\mathbf{1 9}$ & $\mathbf{3 5}$ & $\mathbf{7 3}$ \\
\hline
\end{tabular}

*Presença de 01 forno de cal no NPC.

** Unidade isolada, não constituindo um núcleo de produção da cal.

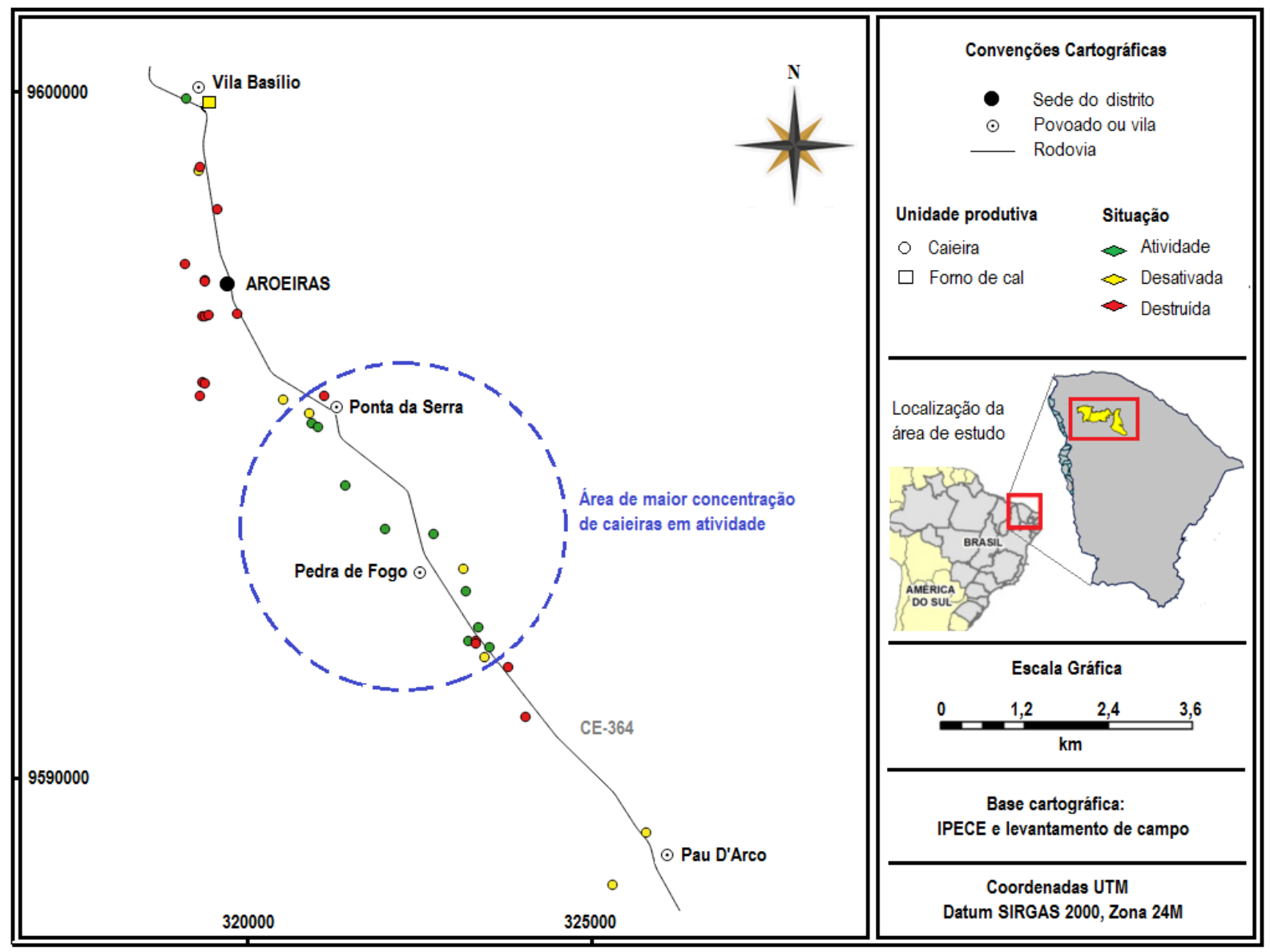

Figura 07: Mapa de distribuição espacial das caieiras e forno de cal do núcleo produtivo Vila Basílio - Pau D’Arco com destaque para a área de maior concentração de caieiras em atividade (2015). Fonte: Elaborado pelo autor, 2019. 
Dentro desse contexto espacial, a maior concentração de caieiras ocorre num intervalo de apenas $8 \mathrm{~km}$ às margens da rodovia CE-364 numa distância não superior a $100 \mathrm{~m}$ da mesma entre as localidades da Ponta da Serra e Pedra de Fogo, ambas pertencentes ao distrito de Aprazível, no município de Sobral, onde existem 09 caieiras em funcionamento, além de inúmeras desativadas e destruídas.

O número de caieiras em funcionamento identificadas em 2015 na referida área revela uma decadência da atividade em relação ao estudo realizado por Albuquerque (2008) na bacia do rio Itacoatiara $\left(133 \mathrm{~km}^{2}\right)$, que abrange a área de maior concentração de caieiras, quando foram identificadas 18 caieiras em atividade em comparação com as atuais 10 unidades, registrando uma redução de 56\% num intervalo de apenas 07 anos.

As duas maiores concentrações espaciais de unidades produtoras de cal da DISAC, o perímetro urbano de Frecheirinha (ANDRADE, 2005) e o NPC Vila Basílio - Pau D’Arco (ALBUQUERQUE, 2008) reduziram de 31 para 14 unidades na última década. Enquanto isso, as inúmeras caieiras das localidades de Martins e Calissas, nas proximidades dos distritos de Aroeiras, apontadas na década de 1980 por BNB (1987) como a principal área de produção do campo Aroeiras atualmente não existem mais (ALBUQUERQUE, 2015).

\section{PERIODIZAÇÃO E ORGANIZAÇÃO ESPACIAL DOS NÚCLEOS DE PRODUÇÃO DA CAL NO CAMPO AROEIRAS}

Do ponto de vista espacial, a atividade da produção da cal na região da DISAC passou por mudanças significativas ao longo do tempo, apresentando diferentes padrões de distribuição e interação espacial nos campos calcários, em especial no campo Aroeiras, foco do presente estudo.

A distribuição e organização espacial das caieiras pode ser periodizada e compreendida em 03 configurações diferentes ao longo do tempo:

- $1^{\circ}$ período: proximidade dos afloramentos rochosos e de corpos hídricos;

- $2^{\circ}$ período: proximidade das áreas urbanizadas e serviços de água e energia;

- $3^{\circ}$ período: proximidade dos principais eixos rodoviários.

Essa configuração temporo-espacial revela a influência de diferentes fatores de atração espacial ao longo do tempo. Nessa análise, os 02 fornos de cal não seguem esse enquadramento, pois além de possuirem um maior nível de investimento econômico, foram frutos de uma política pública estadual obedecendo outros critérios de locação espacial. 
As primeiras caieiras localizavam-se nas proximidades dos afloramentos calcários em função da dificuldade de transporte da rocha das cavas para as mesmas, pois o calcário era transportado em carroças puxadas por animais configurando assim, na primeira organização espacial marcada por um padrão disperso espacialmente. Além disso, a explotação da rocha era manual em todas as etapas, pois, não se utilizava explosivos para não abalar a estrutura das caieiras muito próximas, além da dificuldade de acesso às dinamites.

O principal exemplo dessa etapa no campo Aroeiras são as inúmeras caieiras destruídas presentes na paisagem das localidades de Martins e Calissa, nas proximidades da sede do distrito de Aroeiras (Coreaú). Albuquerque (2015) destaca no contexto regional as caieiras do distrito de Araticum (Ubajara), inserido na mesma organização espacial, porém no campo Frecheirinha.

A segunda organização espacial é consequência direta da evolução no uso dos transportes, de explosivos e de serviços urbanos, mais especificamente pela presença de caminhões e da disponibilidade de energia e água em alguns povoados aumentando assim a capacidade de explotação, transporte, a rapidez e a distância entre a área-fonte do calcário e a área produtora de cal.

O uso de explosivos permitiu a explotação de maiores quantidades acarretando em certa medida, a formação de uma outra organização espacial com alto grau de concentração espacial. Como exemplo dessa organização espacial estão as caieiras destruídas e desativadas nas áreas urbanizadas do distrito de Ubaúna. Atualmente, a expansão urbana da sede do referido distrito aumentou a pressão sobre a atividade reduzindo a apenas 01 (uma) caieira em funcionamento.

Albuquerque (2015) destaca que a cidade de Frecheirinha é exemplo da organização espacial desse período de evolução da atividade, com a presença de inúmeras caieiras destruídas no bairro chamado Caieiral, alusão direta à atividade que lhe deu origem.

Finalmente, o terceiro período é marcado pelo deslocamento das unidades produtoras da cal para as margens das rodovias estaduais e da rodovia federal, à medida que os povoados urbanizaram-se e aumentaram seus efetivos populacionais, gerando conflitos entre as atividades tipicamente urbanas e a poluição advinda das caieiras.

Nesse contexto espacial, podemos citar a atual concentração de caieiras ao longo da CE-364, principalmente entre as localidades de Vila Basílio (Coreaú), passando pelo distrito de Aroeiras, as localidade de Ponta da Serra, Pedra de Fogo e Pau D'Arco, as três últimas já no território do município de Sobral. Albuquerque (2015) destaca que na BR-222 nas 
imediações da cidade de Frecheirinha (campo Frecheirinha) é possível avistar inúmeras caieiras que representam esse padrão de organização espacial.

Segundo Santos (2008), quanto maior a modernidade das atividades, maior a tendência à concentração da mesma em certos pontos do território. A relação direta entre modernidade e concentração espacial pode ser constatada na mineração de subsistência do calcário e beneficiamento pelas caieiras, de um lado e, de outro, a fábrica e a jazida do grupo Votorantim.

A atividade que possuia uma organização espacial muito dispersa e tipicamente rural, atualmente está concentrada linearmente ao longo dos principais eixos rodoviários, assumindo contornos de atividade industrial, apesar da quase inexistente inserção tecnológica. Áreas periurbanas como a sede do distrito de Ubaúna que antes eram repletas de caieiras, atualmente são bairros incorporados a zona urbana desses respectivos espaços.

A atividade da mineração da cal é tão importante regionalmente que induziu a formação de alguns aglomerados populacionais, alguns urbanos, sendo possível registrar 04 níveis de consolidação populacional, no tocante ao início da ocupação e tamanho da localidade: a cidade de Frecheirinha, o distrito de Ubaúna (Coreaú), a localidade de Pedra de Fogo (Sobral) e a vila Basílio (Coreaú) (figura 08).

O maior exemplo é a cidade de Frecheirinha, atualmente com 13.758 habitantes (IBGE, 2018) que, embora fora da área de estudo (15 km da sede do distrito de Ubaúna), cresceu tendo a cal como atividade econômica de maior importância tendo registros no passado de várias caieiras no atual espaço urbano. Registra-se também antigas cavas, atualmente abandonadas no bairro Caieiral e Lapa e completamente inseridas no espaço urbano.

Da mesma forma, mais no nível inferior, o distrito de Ubaúna, que atualmente conta com apenas 01 (uma) caieira em funcionamento já possuiu 04 na atual área urbana onde vivem 3.000 habitantes aproximadamente.

A localidade de Pedra de Fogo, o terceiro exemplo, possui uma população inferior a 1000 habitantes, também possui uma relação muito próxima com a atividade a começar pelo próprio topônimo que faz uma referência ao superaquecimento da rocha ao ser hidratada, tornando-se uma pedra de fogo. No seu arranjo espacial fica clara a distribuição rarefeita das casas, apesar de possuir um núcleo ao redor da igreja católica, porém, sedes de fazendas e o aglomerado "urbanizado" se confundem.

O exemplo de menores proporções espaciais e populacionais é a Vila Basílio com aproximadamente 20 residências que cresceram às margens da CE-364 e o forno de cal da vila 
nas proximidades do distrito de Aroeiras, a partir de 1994 com a construção do mesmo. Como forma de ampliar a renda, as pessoas que ali instalaram-se construíram ao lado das casas uma caieira ainda em atividade, diferentemente, do forno de cal.

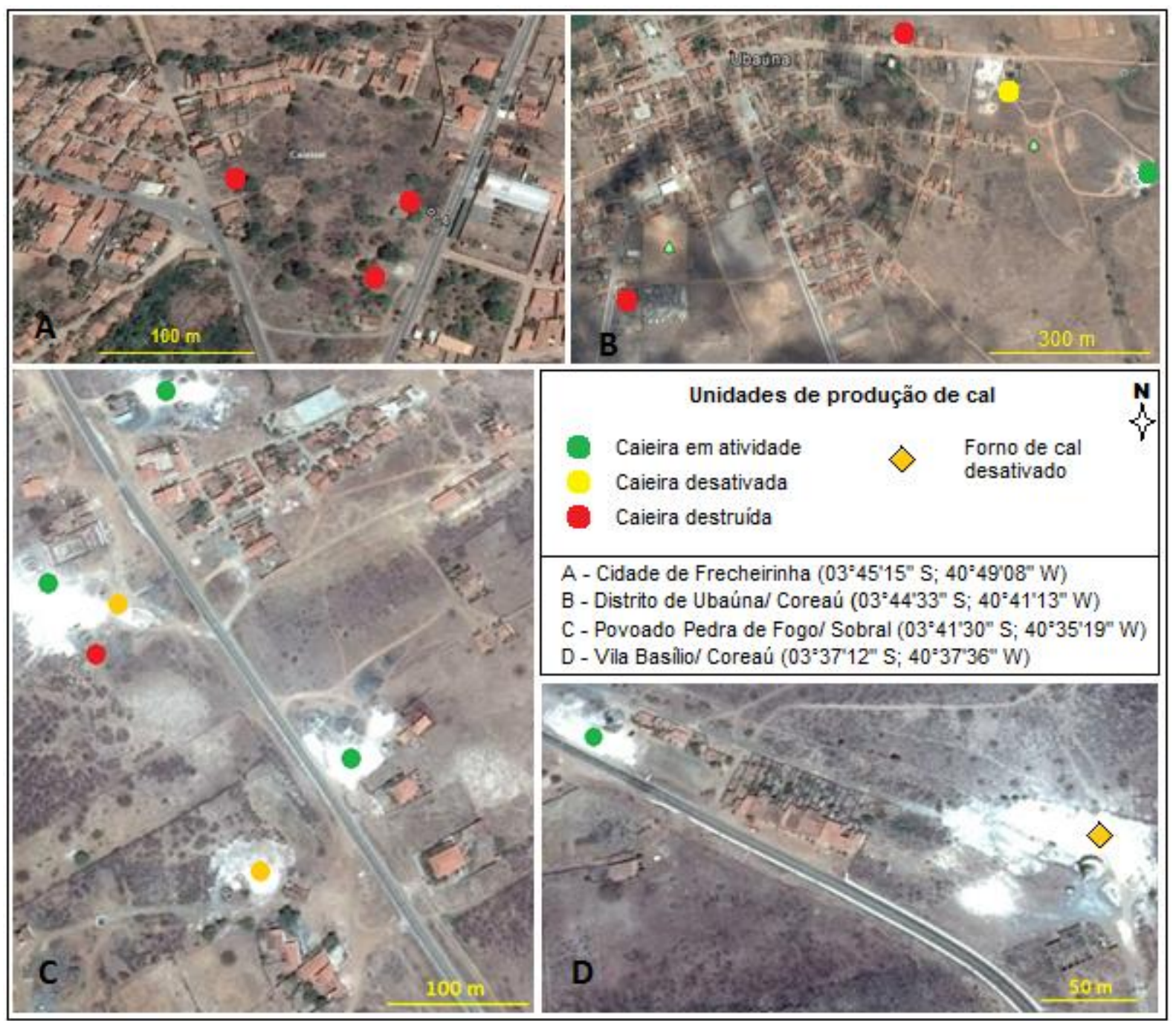

Figura 08: Diferentes níveis de relação das caieiras com aglomerados populacionais:

(A) Frecheirinha, (B) Ubaúna, (C) Pedra de Fogo e (D) Vila Basílio. Fonte: Adaptado de Google Earth (out/2013).

Quanto menor a localidade, mais recente é o processo de ocupação das caieiras e menores são os conflitos da atividade com as residências, muito em função das relações interpessoais mais próximas entre as pessoas e entre patrão e empregados.

Atualmente, o campo calcário Aroeiras configura-se como o campo de maior atividade econômica, diferente da década de 1980, conforme estudo de BNB (1987), quando o campo Frecheirinha ocupava essa posição. Além da maior atividade econômica com 19 caieiras em funcionamento, o referido campo abriga a jazida da fábrica de cimento Poty. 
Do outro lado, no campo calcário Frecheirinha, Albuquerque (2015), aponta uma decadência vertiginosa do número de caieiras, em detrimento do aumento das fábricas de confecção de moda íntima que, a partir da elevada produção e do número de empregos gerados na região, inclusive em áreas tradicionais na produção da cal como Ubaúna (Coreaú) e São José do Torto (Sobral), consolida a cidade de Frecheirinha como uma nova centralidade econômica regional reestruturando o território a partir do setor terciário e não mais secundário.

\section{CONSIDERAÇÕES FINAIS}

O geossistema do campo calcário Aroeiras e adjacências possui 73 unidades de produção de cal, sendo 71 caieiras e apenas 02 fornos de cal, das quais apenas $1 / 3$ estão em funcionamento evidenciando uma decadência da atividade de importância histórica e econômica para a região. Porém, as caieiras e fornos de cal desativadas e destruídas são verdadeiras rugosidades nas paisagens da porção leste da Depressão Interplanáltica Semiárida do Alto Coreaú, mais exatamente no campo calcário Aroeiras demarcado por um quadrilátero cujos vértices são os distritos coreauenses de Aroeiras e Ubaúna e, sobralenses de Aprazível e São José do Torto formando um território produtivo que tem vivenciado grandes transformações.

É perceptível a concentração da metade das caieiras em funcionamento no núcleo Vila Basílio - Pau D'Arco, mais exatamente entre os $08 \mathrm{~km}$ que separam as localidades de Ponta da Serra e Pedra de Fogo ao longo da rodovia CE-364 no município de Sobral, aliado à extinção da atividade no distrito de Aroeiras.

A atual organização espacial é marcada pela concentração de caieiras ao longo dos principais eixos rodoviários, sejam eles federal, estadual ou municipal distanciando-se dos principais núcleos populacionais reduzindo conflitos com a população por conta da fumaça tóxica no processo de combustão e do pó calcário no processo de hidratação da rocha.

Para finalizar, é notório a decadência da atividade artesanal da produção da cal na região, decorrente da baixa inserção tecnológica, baixos preços da cal e elevada demanda por lenha para combustão dos fornos, fatores esses associados à reestruturação produtiva regional liderada pela feira permanente de confecção do distrito de Aprazível e pelas fábricas de moda íntima na cidade de Frecheirinha, esta última, antigo pólo de produção da cal. 


\section{REFERÊNCIAS BIBLIOGRÁFICAS}

ALBUQUERQUE, F. N. B. Mineração, degradação ambiental e desertificação na Bacia do Rio Itacoatiara, noroeste do Estado do Ceará. Rio de Janeiro: UFRJ. Dissertação (Mestrado em Geografia). 2008. $138 \mathrm{f}$.

Recurso natural, organização espacial e ordenamento territorial: mineração e degradação de terras na Depressão Interplanáltica Semiárida do Alto Coreaú (CE). Rio Claro: IGCE-UNESP. Tese (Doutorado em Geografia). 2015. 223 f.

AMARAL FILHO, Jair; SCIPIÃO, Tatiana Teófilo. Panorama geral do setor mineral cearense. Fortaleza: SEPLAN: IPECE. Jul/2004 (nota técnica 09).

ANDRADE, J. K. C. Diagnóstico sócio-ambiental da atividade de fabricação da cal em fornos artesanais no município de Frecheirinha/CE. Fortaleza: UECE. Dissertação (Mestrado em Desenvolvimento em Meio Ambiente). 2005.

BANCO DO NORDESTE DO BRASIL. A indústria de calcários e dolomitos no Nordeste. Fortaleza: BNB/ETENE. 1987. (Série: Estudos econômicos e sociais, 34).

BERTALANFFY, L. Teoria geral dos sistemas - fundamentos, desenvolvimento e aplicações. 5. Ed. Petrópolis: Vozes. 2010.

BERTRAND, G. Paisagem e Geografia Física global: esboço metodológico. São Paulo, Instituto de Geografia. USP. 27 p. 1972. (Cadernos de Ciências da Terra, 13)

A Geografia Física: de um paradigma perdido a um paradigma re-encontrado? (notas). Anais do VII Simpósio Brasileiro de Geografia Física Aplicada - vol. I. Curitiba. 1997. p. $03-05$.

BRASIL. Departamento Nacional da Produção Mineral. Projeto RadamBrasil. Folha SA.24 Fortaleza. IBGE, Rio de Janeiro. 1981.

CHRISTOFOLETTI, A. Modelagem de sistemas ambientais. São Paulo: Edgar Blücher. 1999. $236 \mathrm{p}$.

CORREA, R. L. Região e organização espacial. 7. ed. São Paulo: Ática. 2000.

MARTEN, G. G. Ecología Humana: Conceptos básicos para el desarrollo sustentable. Earthscan Publications. 2001. Disponível em: http://gerrymarten.com/ecologiahumana/indice.html. Acesso em: 03 mar 2014.

MONTEIRO, C. A. F. Geossistema - a história de uma procura. São Paulo: Contexto. 2003. (Coleção Novas Abordagens, Geousp 3).

MORIN, E. O método - a natureza da natureza. 2. Ed. Porto Alegre: Sulina. 2008. 
PEREZ FILHO, A. Sistemas ambientais e sociedade. In: OLIVEIRA, M. P; COELHO, M. C. N; CORRÊA, A. M. (org.). O Brasil, a América Latina e o Mundo: Espacialidades Contemporâneas (I). Rio de Janeiro: Lamparina, 2008, v. 1, p. 362-372.

RODRIGUES, C. Teoria geossistêmica e sua contribuição aos estudos geográficos e ambientais. Revista do Departamento de Geografia, 14 (2001) 69-77.

RODRIGUEZ, J. M; SILVA, E. V. Planejamento e gestão ambiental: subsídios da Geoecologia das Paisagens e da Teoria Geossistêmica. Fortaleza: Edições UFC. 2013.

Teoria dos geossistemas - o legado de V. B. Sochava. Vol. 1 - Fundamentos teórico-metodológicos). Fortaleza: Edições UFC. 2019.

SANTOS, M. O espaço dividido. São Paulo: Edusp. 2008.

SINDICAL. Sindicato das Indústrias de Cal do Estado do Paraná. Histórico. Disponível em: http://www.fiepr.org.br/sindicatos/sindicalpr/historico-1-3302-19867.shtml. Acesso em:

SOTCHAVA, V. B. O estudo do geossistema. Trad. MONTEIRO, C. A. F.; ROMARIZ, D. A. São Paulo: IG-USP. 1977.

TROPPMAIR, H; GALINA, M. H. Geossistemas. Mercator - Revista de Geografia da UFC, ano 05, número 10, 2006.

Recebido em: 19/08/2019

Aceito para publicação em: 01/11/2019 